\title{
Progress of preoperative and postoperative radiotherapy in gastric cancer
}

\author{
Nan Zhang ${ }^{1+}$, Qian Fei ${ }^{1,2 \dagger}$, Jiajia Gu', Li Yin ${ }^{1,2}$ and Xia He $\mathrm{H}^{1,2^{*}}$
}

\begin{abstract}
Background: Gastric carcinoma, a highly common malignant tumor, is treated mainly by surgery. Meanwhile, radiotherapy is attracting increased attention as a crucial locoregional therapy. However, the application of radiotherapy in gastric carcinoma is still limited and radiation standards remain debatable.

Main body: The use of preoperative radiotherapy for treating gastroesophageal junction cancer has advanced. However, additional phase III clinical trials are needed to further verify the therapeutic value of preoperative radiotherapy for gastric cancer. Patients with D1 or D1 plus lymphadenectomy can benefit from postoperative radiotherapy obviously, and postoperative radiotherapy may be effective for patients with D2 lymphadenectomy with a high $\mathrm{N}$ stage. The target volume delineation of preoperative and postoperative radiotherapy should be based on clinical experience and the characteristics of lymphatic drainage.
\end{abstract}

Conclusions: With the advancement of radiotherapy technology, preoperative and postoperative radiotherapy are becoming increasingly accepted as important auxiliary treatments for gastric cancer.

Keywords: Gastric carcinoma, Radiotherapy, Radiation field, D2 lymph node dissection

\section{Background}

The morbidity of gastric cancer has been declining worldwide but remains a highly common malignancy, which is the third leading cause of cancer-related mortality. In 2012, one million new cases occurred around the world, with more than 72,000 deaths [1]. More than $75 \%$ newly diagnosed patients were in an advanced stage because of the lack of the typical clinical premonitory symptoms of gastric cancer. Advanced stage means the tumor has invaded the muscle layer or lymph node, and the survival rates of patients in this stage are only $20-50 \%$ [2]. Among patients with advanced stage gastric cancer, approximately $50 \%$ have lost the chance of surgery. Therefore, comprehensive treatment based on radiotherapy (RT) and chemotherapy has recently received much attention.

In recent years, the application of RT in gastric cancer has become increasingly common with the development

\footnotetext{
* Correspondence: hexiabm@163.com

${ }^{\dagger}$ Nan Zhang and Qian Fei contributed equally to this work.

'Department of Radiation Oncology, Jiangsu Cancer Hospital \& Jiangsu Institute of Cancer Research \& Affiliated Cancer Hospital of Nanjing Medical University, Nanjing Medical University Affiliated Cancer Hospital, 42 Baiziting, Nanjing 210009, Jiangsu, China

${ }^{2}$ The Fourth Clinical School of Nanjing Medical University, Nanjing, China
}

of radiation technology. In 2001, John et al. published the results of the INT0116 trial in the New England Journal and caused the RT change from the traditional palliative treatment to important adjuvant therapy in the multidisciplinary treatment for gastric cancer [3].

\section{Preoperative RT}

Preoperative RT is mainly used to reduce tumor burden in patients with advanced gastric cancer. This process enables inoperable patients to be eligible for operation. In addition, preoperative RT may play a unique role in controlling micrometastasis, and the pathological response after preoperative RT may provide important prognostic information $[4,5]$. The results of several major clinical trials showed that gastroesophageal junction (GEJ) cancer achieves a better therapeutic effect than that of gastric cancer in terms of preoperative RT (Table 1).

In 1998, Chinese researchers found that 370 patients with GEJ cancer treated with preoperative RT significantly improved in tumor resection rate relative to the patients treated with surgery alone $(89.5 \%$ vs. $74.9 \%)$. The local control rates in the two groups were $61 \%$ and $45 \%(P<0.05)$, and the 10 -year survival rates were $20.3 \%$ 
Table 1 Preoperative RT III clinical trials

\begin{tabular}{|c|c|c|c|c|c|}
\hline Study/institute & $n$ & Tumor location & Groups & Local control & Survival \\
\hline $\begin{array}{l}1998 \\
\text { Zhang et al. [6] }\end{array}$ & 370 & EGJ & RT+S vs. S & Local control and local recurrence rate $61.4 \%$ vs. $51.7 \%$ & $\begin{array}{l}\text { 10-year OS } \\
20.3 \% \text { vs. } 13.3 \%\end{array}$ \\
\hline $\begin{array}{l}2009 \\
\text { Stahl et al. [7] }\end{array}$ & 119 & EGJ & $C R T+S$ vs. $C+S$ & Pathological complete response rate $15.6 \%$ vs. $2.0 \%$ & $\begin{array}{l}\text { 3-year OS } \\
47.4 \% \text { vs. } 27.7 \%\end{array}$ \\
\hline $\begin{array}{l}2012 \\
\text { Van Hagen et al. [8] }\end{array}$ & 366 & $\mathrm{EGJ}$ or EC & CRT+S vs. S & Local recurrence rate $14 \%$ and $34 \%$ & $\begin{array}{l}5 \text {-year OS } \\
47 \% \text { vs. } 34 \%\end{array}$ \\
\hline $\begin{array}{l}2002 \\
\text { Skoropad et al. [9] }\end{array}$ & 102 & GC & $R T+S$ vs. S & No sense & No sense \\
\hline
\end{tabular}

$E G J$ esophagogastric junction, GC gastric cancer, $E C$ esophagus cancer, $R T$ radiotherapy, $C R T$ concurrent radiotherapy, $S$ surgery

and $13.3 \%(P=0.009)$, respectively. These results indicate that preoperative RT may be beneficial for improving the local control rate and the overall survival (OS) of patients with GEJ cancer [6]. Stahl revealed that preoperative RT significantly improved the rate of pathological complete response (15.6\% vs. $2.0 \%)$ of GEJ adenocarcinoma and increased the 3-year OS rate (47.4\% vs. $27.7 \%, P=0.07$ ) [7]. Similarly, Hagen and co-workers investigated 366 cases of gastric cancer or GEJ cancer and found that the patients treated with preoperative radiochemotherapy (carboplatin + paclitaxel, 5 weeks; 41.4 Gy/23 f, 5 days/week) attained a significantly improved rate of tumor resection ( $92 \%$ vs. $69 \%, P$ $<0.001)$ and OS (49.4 months vs. 24 months, median survival) relative to those of the patients treated with surgery alone. Besides, preoperative radiochemotherapy was related to a decreased rate of local recurrence (LRRs, $14 \%$ and $34 \%, P<0.001$ ) and distant metastases rates $(29 \%$ and $35 \%, P=0.025)$ relative to surgery [8]. In this study, the regimen above became the recommended treatment program for GEJ adenocarcinoma in the USA.

Compared with the progress of preoperative RT in treating GEJ cancer, the application of preoperative RT still lacks large-scale phase III clinical trials for gastric cancer. In 2002, Skoropad investigated 102 cases of resectable gastric cancer and found that preoperative RT (20 Gy/5 f) did not significantly improve the local control and long-term survival relative to surgery alone (20-year OS rates, $32 \%$ and $18 \%, P=0.555$ ) [9]. In this study, the irradiation technology was regressive despite the follow-up time of 20 years, and the number of cases was minimal. Conversely, some single-arm prospective trials and retrospective analyses confirmed that adopting preoperative chemoradiotherapy (CRT) appeared safe and beneficial for advanced gastric cancer patients [1016]. Kumagai presented results indicating that patients with gastric or GEJ cancer treated with preoperative RT or CRT attained a higher rate of survival than those patients treated with surgery alone. Simultaneously, he found that adding preoperative RT or CRT did not significantly decrease the rates of postoperative recurrence and mortality [15].
The response of preoperative chemotherapy in gastric cancer has been universally accepted, but whether preoperative concomitant radiochemotherapy can offer survival benefits is unclear relative to preoperative chemotherapy alone [17-19]. The ongoing TOPGEAR clinical trial is designed to address this issue [20]. In addition, a phase II clinical trial (NCT02301481) is being conducted by the Chinese Academy of Medical Sciences to determine whether preoperative radiochemotherapy is superior to preoperative chemotherapy alone for advanced gastric adenocarcinoma patients. A similar clinical study (NCT01815853) is conducted at the Sun Yat-sen University to observe the OS and safety of the preoperative radiochemotherapy. These results of the clinical trials are promising [21].

\section{Postoperative RT}

The findings of the INT0116 trial show the important role of postoperative RT in the adjuvant treatment of gastric cancer [3]. However, many deficiencies, such as the lack of the strict control of surgical type (only $10 \%$ cases of D2 dissection), the backwardness of radiation technology, and the low treatment compliance, are observed in research. After the Lancet published the 15-year follow-up results of D1 and D2 dissection in 2010, the advantage of reducing the local recurrence caused D2 to gradually become the standard surgical operation of resectable advanced gastric cancer [22]. The following section is mainly based on the current situation of postoperative RT after D2 dissection. The main results of phase III clinical trials in recent years are displayed in Table 2.

In 2012, the 10-year follow-up results of INT0116 showed that postoperative concurrent radiochemotherapy continued its survival benefit and that either the D1 or the D2 subgroup can benefit from this modality [23]. Simultaneously, researchers from South Korea presented results of the ARTIST trial, which showed that the postoperative RT did not significantly improve the rate of disease-free survival (DFS), but for patients with pathologic positive lymph nodes, the postoperative RT demonstrated its survival benefits with no statistical significance $(P=0.38)$ 
Table 2 Postoperative RT III clinical trials

\begin{tabular}{|c|c|c|c|c|c|c|c|c|}
\hline Study/institute & $n$ & D2 & RT & $\mathrm{pN}+$ & III-IV & DFS/RFS & OS & Remarks \\
\hline $\begin{array}{l}2001 \text { INT0116 } \\
\text { USA [3] }\end{array}$ & 556 & $10 \%$ & $2 \mathrm{D}$ & $85 \%$ & NR & $\begin{array}{l}3 \text {-year } 48 \% \text { vs. } 31 \% \\
(p<0.001)\end{array}$ & $\begin{array}{l}3 \text {-year } 50 \% \text { vs. } 41 \% \\
(p=0.005)\end{array}$ & \\
\hline 2012 INT0116 [23] & & & & & & 10-year similar & 10-year similar & D1 and D2 benefit \\
\hline $\begin{array}{l}2012 \text { ARTIST } \\
\text { South Korea [24] }\end{array}$ & 458 & $100 \%$ & $2 \mathrm{D}$ or $3 \mathrm{D}$ & $86 \%$ & $41 \%$ & $\begin{array}{l}3 \text {-year } 78 \% \text { vs. } 74 \% \\
(p=0.0862)\end{array}$ & NR & $\mathrm{N}^{+}$DFS benefit \\
\hline $\begin{array}{l}2015 \text { ARTIST } \\
\text { Final report [25] }\end{array}$ & & & & & & $\begin{array}{l}5 \text {-year } 74 \% \text { vs. } 68 \% \\
(p=0.092)\end{array}$ & $\begin{array}{l}5 \text {-year } 75 \% \text { vs. } 73 \% \\
(p=0.527)\end{array}$ & $\begin{array}{l}\mathrm{N}^{+} \text {and } \mathrm{GC} \\
\mathrm{DFS} \text { benefit }\end{array}$ \\
\hline $\begin{array}{l}2012 \text { NCC } \\
\text { South Korea [26] }\end{array}$ & 90 & $100 \%$ & $2 \mathrm{D}$ or $3 \mathrm{D}$ & $98 \%$ & $100 \%$ & 5 -year $65 \%$ vs. $55 \%(p>0.05)$ & $\begin{array}{l}5 \text {-year } 65 \% \text { vs. } 55 \% \\
(p>0.05)\end{array}$ & $\begin{array}{l}\text { LRRFS and } \\
\text { III stage DFS benefit }\end{array}$ \\
\hline $\begin{array}{l}2012 \text { IMRT } \\
\text { China [27] }\end{array}$ & 351 & $100 \%$ & NR & $86 \%$ & $71 \%$ & $\begin{array}{l}5 \text {-year } 45 \% \text { vs. } 36 \% \\
(p=0.029)\end{array}$ & $\begin{array}{l}5 \text {-year } 48 \% \text { vs. } 42 \% \\
(p=0.122)\end{array}$ & \\
\hline
\end{tabular}

NR not reported, OS overall survival, DFS/RFS disease-/relapse-free survival, LRRFS locoregional failure-free survival, GC gastric cancer

[24]. The final results of the ARTIST trial after a 7-year follow-up also yielded similar conclusions [25]. In 2012, two other phase III clinical trials from Korea and China revealed that the postoperative $\mathrm{RT}$ after $\mathrm{D} 2$ dissection did not improve OS but enhanced the rate of local recurrence-free survival [26, 27]. In 2017, Stumpf et al. analyzed 3656 patients with resected gastric adenocarcinoma from the National Cancer Database in 2004 to 2012 and compared the OS rates between the perioperative chemotherapy group and the postoperative adjuvant radiochemotherapy group. The results of univariate and multivariate analyses suggested that the OS rates in the postoperative adjuvant radiochemotherapy group were superior to those of the perioperative chemotherapy group. In the subgroup analysis, the patients with positive surgical margins benefited more with adjuvant RT [28].

Given the analysis of the above phase III clinical trials, the trend toward negative results for the three trials, which are from the east, may be explained by the wide use of D2 dissection and postoperative chemotherapy. The lymph node dissection is substantial in D2. Hence, for some patients, treatment with D2 dissection plus postoperative chemotherapy is sufficient. On the contrary, the positive results of INT0016 were mainly for the vast majority of patients treated with D1 dissection, in which the lymphatic dissection range is minimal; thus, postoperative RT can play an important role in terms of local control. Hence, patients with gastric cancer require being screened before receiving postoperative RT [1].

In our opinion, whether patients require adding RT after D2 dissection should be determined by the disease stage. Sasako found that for patients with high-stage gastric cancer, postoperative chemotherapy alone cannot improve the RFS [29]. Therefore, adding RT for stage III gastric cancer patients after D2 dissection is necessary. In the ARTIST trial, only $41 \%$ of the patients were diagnosed at the III-IV stage, and postoperative RT may be an over-treatment for patients with stages I-II, where postoperative chemotherapy alone was sufficient. Therefore, the patients with pathologically positive lymph nodes in the ARTIST trial did not significantly improve in DFS, whereas for the patients with higher stages, especially stage III, the advantages of postoperative RT for local control were prominent. In an American retrospective review of 23,461 patients with early gastric cancer (IB-II) treated with postoperative RT, Datta concluded that patients in all stages of early gastric cancer can acquire survival benefits [30]. However, the researchers did not clarify whether the surgical patients were treated with D1 or D2 dissection. Well-designed prospective randomized clinical trials are still required to validate whether patients in different stages of gastric cancer with pathologic positive lymph nodes can benefit from postoperative RT.

The latest gastric cancer NCCN guidelines (2018.V1) still recommend postoperative chemotherapy after D2 lymphadenectomy, and postoperative CRT is preferred for surgical patients with a range of resection less than D2. The ARTIST II trial is a phase III randomized trial of adjuvant chemotherapy with compound tegafur-oteracil potassium capsules (S-1) versus $\mathrm{S}-1$ /oxaliplatin $\pm \mathrm{RT}$ for surgical patients with positive nodes [31]. Remarkably, the results of the phase II clinical trial based on S-1 and cisplatin showed that the postoperative concurrent CRT group improved 3 years of DFS relative to the postoperative chemotherapy group, and the toxicities were acceptable [32]. In recent years, several meta-analyses have demonstrated the role of perioperative RT in treating gastric cancer [33-35].

In summary, RT can be used as an important adjuvant therapy during the perioperative period of patients with surgical gastric cancer in an advanced stage, especially for some specific patients after D2 dissection, which effectively improves the PFS and reduces the rate of local recurrence. The value of preoperative RT in gastric cancer still requires further validation, and we anticipate further results of relevant randomized controlled clinical trials. In addition, the screening of tumor-derived radiosensitivity markers has attracted increasing attention in 
recent years. For example, positive E2F-1 expression and negative HER2 expression may indicate that the patients with gastric cancer treated with postoperative CRT will achieve a good outcome, and in vitro studies have shown that CHK1 overexpression may be associated with radiation resistance [36-38]. Therefore, these markers can be assumed to be used as new risk factors for predicting the survival outcome of gastric cancer patients to select those who may benefit from the perioperative period RT.

\section{Progress of treatment volume range Preoperative target volume}

Previous preoperative target volume includes the whole stomach and large node areas (paraesophageal, extending from the trachea for bifurcation and the lesser curvature of the stomach to the posterior second thoracic vertebra) because of a lack of consolidated phase III clinical trials to define the target volume of gastric cancer. In 2009, EORTC-ROG (European Organization for Research on the Treatment of Cancer) redefined the CTV of GEJ adenocarcinoma and gastric adenocarcinoma, which reduced the error [39]. The therapeutic efficacy of the preoperative RT in gastric cancer has not reached a consensus; therefore, we only analyzed the target volume of GEJ cancer or proximal gastric cancer in this study.

The stomach is a hollow organ, and its position may be influenced by respiratory motion and body movement. The reduction of error of CTV caused by swinging and breathing has become our primary task. Stahl assumed that the CTV includes a 5-cm margin of the proximal primary tumor, a 3-cm margin of the distal primary tumor, and a $1-\mathrm{cm}$ margin of all nodal areas at risk [7]. The PTV margin of $8 \mathrm{~mm}$ expanded in all directions from the CTV to reduce the systematic error and target displacements. Hagen et al. defined PTV as the 4-cm margin of the primary tumor [8]. In 2009, the expert opinions of specialists in EORTC-ROG highlighted their definition of PTV as the $1-\mathrm{cm}$ margin of the proximal and transverse CTV, which is the $1.5-\mathrm{cm}$ margin of the distal CTV, to reduce the error; this definition is similar to those of the above two studies, given the lack of sufficient evidence to set the criteria for the target volume [39].

In accordance with Siewert's classification, the opinions of specialists in EORTC-ROG (2009) proposed a lymphatic drainage in different types of GEJ cancer; this proposal provided clinicians with a reference for delineating the target volume. However, the opinions failed to combine with computed tomography (CT) scans or other radiographic studies. Additionally, the patterns of local regional recurrence for gastric cancer were disregarded.
In 2014, on the basis of the study of Hagen, Oppedijk suggested patterns of recurrence for esophageal or GEJ cancer after preoperative radiochemotherapy [40]. After at least 24 months of follow-up, the overall recurrence rates of the surgery group and the CRT plus surgery group were $58 \%$ and $35 \%$, respectively. The LRR of the $\mathrm{CRT}+\mathrm{S}$ group reduced from 34 to $14 \%$. A total of $5 \%$ of the patients of the preoperative CRT group experienced local relapse within the irradiated field; $2 \%$ experienced a local relapse at the edge of the irradiated field; $6 \%$ experienced local relapse outside the irradiated field. In this study, disease relapse mainly occurred in the celiac lymph nodes, para-aortic lymph nodes, and peritoneum, which were associated with the distal esophagus and esophagogastric junction (EGJ) cancer. However, the patients with EGJ cancer only constituted one-fourth, which may have an implication in delineating the high-risk areas of recurrence in EGJ cancer.

Oppedijk found that the incidence of local relapse outside the irradiated field remains high, and expanding the target volume for preoperative RT is necessary. Furthermore, we still lack reliable evidence for delineating the clinical target volume for preoperative RT in GEJ adenocarcinoma, and large-scale clinical trials on regional lymph node recurrence and failure modes are required.

\section{Postoperative target volume}

Developing a uniform standard for the delineation of the postoperative RT target volume is difficult because of the different sites, stages, and lymphatic metastases in gastric cancer; the various surgical methods, and the dissimilar conditions of postoperative cutting edge. The earliest guideline for defining the target volume for postoperative RT that was based on the primary tumor sites and the pathway of lymph node metastasis was proposed by Smalley and Tepperin [41, 42]. However, the guideline was recommended for D1 or D1 + lymphadenectomy and during the era of 2D RT techniques with adverse reactions and low local control rates. This article mainly discusses the target volume after D2 lymphadenectomy.

Nam retrospectively analyzed 291 patients after D2 dissection. A total of 83 target volumes of patients included the gastric stump, whereas the remaining 208 did not. The results showed that no significant differences in 5-year OS and DFS existed between these two groups. However, 3-4 grade diarrhea was more common in the patients with target volumes that included the gastric remnant. Therefore, Nam suggested that the target volume should exclude the gastric stump for patients treated with D2 dissection [43]. As found previously, the ARTIST trial also excluded the gastric stump from the irradiated field. Aside for the temporary adverse effects, the long-term survival of patients, especially the 
occurrence of gastric stump cancer, must also be monitored. Ohira found that the average interval of occurrence of gastric stump cancer was $6.8-18.8$ years, but the follow-up period was only 5 years in the study of Nam [44]. The occurrence of postoperative gastric stump carcinoma should be of particular concern, although no report has explored the relationship between postoperative RT and gastric stump cancer. Furthermore, the study of Nam adopted the traditional 2D RT with added adverse reactions, but modern radiation technology has a unique advantage in reducing adverse reactions. In the NCC trial, the patients with irradiated fields that included the gastric stump obtained a high dose in the left renal area. Another study from China, namely, the intensity-modulated radiation therapy (IMRT) trial, demonstrated that with advanced IMRT technology, the toxic side effects caused by radiation exposure to the remnant stomach can be controlled.

Except for the ARTIST trial, almost all the phase III trials defined node nos. $1-16$ as node areas at risk (Table 3, Fig. 1). The node areas at risk in the ARTIST trial only included node nos. 7-9 and 12-16, which received a reduced dose exposure to the intestinal tract. Besides, no difference existed between surgery plus RT and chemotherapy alone in adverse reactions. This result implies that the traditional node areas at risk may be exceedingly large for gastric cancer. Selective RT to high-risk lymph nodes should agree with the patterns of lymph nodes (LNs) recurrence after D2 dissection, which further optimizes the target volume. In 2012, Chang retrospectively investigated 357 gastric cancer patients with stage III after D2 or D3 dissection [45]. The results showed that the peritoneum was the most common site of recurrence, and the most common recurrent LNs was outside the field of D2 dissection (node nos. 12-16). Node nos. 16a as well as 16b are the most common recurrent lymph node whatever the site of primary tumor is.
Yoon retrospectively analysed the follow-up records from 91 stage III gastric carcinoma patients with the N3 disease, who were diagnosed with the first regional relapse after D2 dissection [46]. This study suggested that vessel-based delineations of rnGTVs (recurrent nodal gross tumor volume) on CT images depend on the recurrent sites of LNs from the follow-up records after D2 lymphadenectomy. The results showed that no. 16a (58.2\%) and 16b (61.5\%) were the most commonly affected first recurrent LNs. In addition, node nos. 9, 12, 13 , and 14 were involved in $15.4 \%, 28.6 \%, 15.4 \%$, and $19.8 \%$ of patients, respectively. Conversely, node nos. 11 (7.0\%), $8(3.0 \%), 2(2.0 \%)$, and $10(1.0 \%)$ were less commonly involved. When tumor involved the proximal third of stomach, the most commonly involved LNs were nos. 9 (30\%), $10(10 \%)$, and $13(10 \%)$ lymph nodes. Nos. 12 and 14 were the most commonly involved LNs, when tumor involved the middle third stomach $(26 \%$ and $13 \%$, respectively). When tumor involved the distal third stomach, nos. 12, 13, 14, 9, and 11 were the commonly involved metastatic LNs (39\%, 27.0\%, 20.0\%, $20.0 \%$, and $10 \%$, respectively). Nos. 14, 12, 11, 9, and 2 were the commonly involved metastatic LNs (41\%, $24.0 \%, 12 \%, 12 \%$, and $12 \%$, respectively), when tumor involved more than two-thirds of the stomach. It showed that, in this study, the recurrent sites of lymph nodes such as splenic hilum, perigastric area, and below IMA were uncommon. The treatment volume can exclude the liver hilum (no. 12), perigastric area (nos. 1-6), and anterior part of the SMA (no. 14) when tumor involved the proximal third of the stomach; nevertheless, if CTV encompassed the splenic hilum (no. 10), it should also contain the splenic artery region. The treatment volume should include the perigastric region (nos. 1-6), the splenic hilum (no. 10), and the splenic artery region (no. 11 ) in the middle or distal third stomach. In addition, when patients with extensive tumor involved more than two-thirds of the stomach were only treated with

Table 3 Postoperative RT III clinical trials, toxic reactions, and target volume

\begin{tabular}{|c|c|c|c|c|c|}
\hline Study/institute & $\begin{array}{l}\text { RT dose } \\
\text { (Gy) }\end{array}$ & Intervention & Severe toxicity & Target volume & $\begin{array}{l}\text { Completed } \\
\text { rate }\end{array}$ \\
\hline $\begin{array}{l}2001 \text { INT0116 } \\
\text { USA [3] }\end{array}$ & 45 & $\begin{array}{l}\text { CRT, 45Gy, 5FU } \\
+\mathrm{LV}\end{array}$ & $\begin{array}{l}\text { Grade } 3+, 41 \%, \\
\text { Grade } 4+, 32 \%\end{array}$ & $\begin{array}{l}\text { Tumor bed, regional node (nos. 1- } \\
\text { 16) }\end{array}$ & $63 \%$ \\
\hline $\begin{array}{l}2012 \text { ARTIST } \\
\text { South Korea } \\
\text { [24] }\end{array}$ & 45 & $\begin{array}{l}\text { CT-CRT-CT, CRT: } \\
\text { Capecitabine; CT: } \\
\text { XP }\end{array}$ & Similar to chemotherapy alone & $\begin{array}{l}\text { Tumor bed in T4 LN (nos. 7-9 and } \\
\text { 12-16) }\end{array}$ & $82 \%$ \\
\hline $\begin{array}{l}2012 \text { NCC } \\
\text { South Korea } \\
\text { [26] }\end{array}$ & 45 & CRT, 5FU+LV & $\begin{array}{l}\text { Grade } 3+\text { hematologic toxicities; } 20 \% \text { vs. } 25 \% \\
\text { G3+Gl; } \\
17 \% \text { vs. } 11 \%\end{array}$ & $\begin{array}{l}\text { Tumor bed, regional node (nos. 1- } \\
\text { 16) }\end{array}$ & $87 \%$ \\
\hline $\begin{array}{l}2012 \text { IMRT } \\
\text { China [27] }\end{array}$ & 45 & $\begin{array}{l}\text { CRT, 45Gy, 5FU } \\
+\mathrm{LV}\end{array}$ & Similar toxicity mostly well tolerated & $\begin{array}{l}\text { Tumor bed, regional node (nos. 1- } \\
\text { 16) }\end{array}$ & $91 \%$ \\
\hline
\end{tabular}

CRT chemoradiotherapy, CT chemotherapy, 5-FU 5-fluorouracil, LV leucovorin, XP capecitabine plus cisplatin, 2D 2-dimentional irradiation, 3D 3-dimensional conformal radiation therapy, IMRT intensity-modulated radiation therapy 


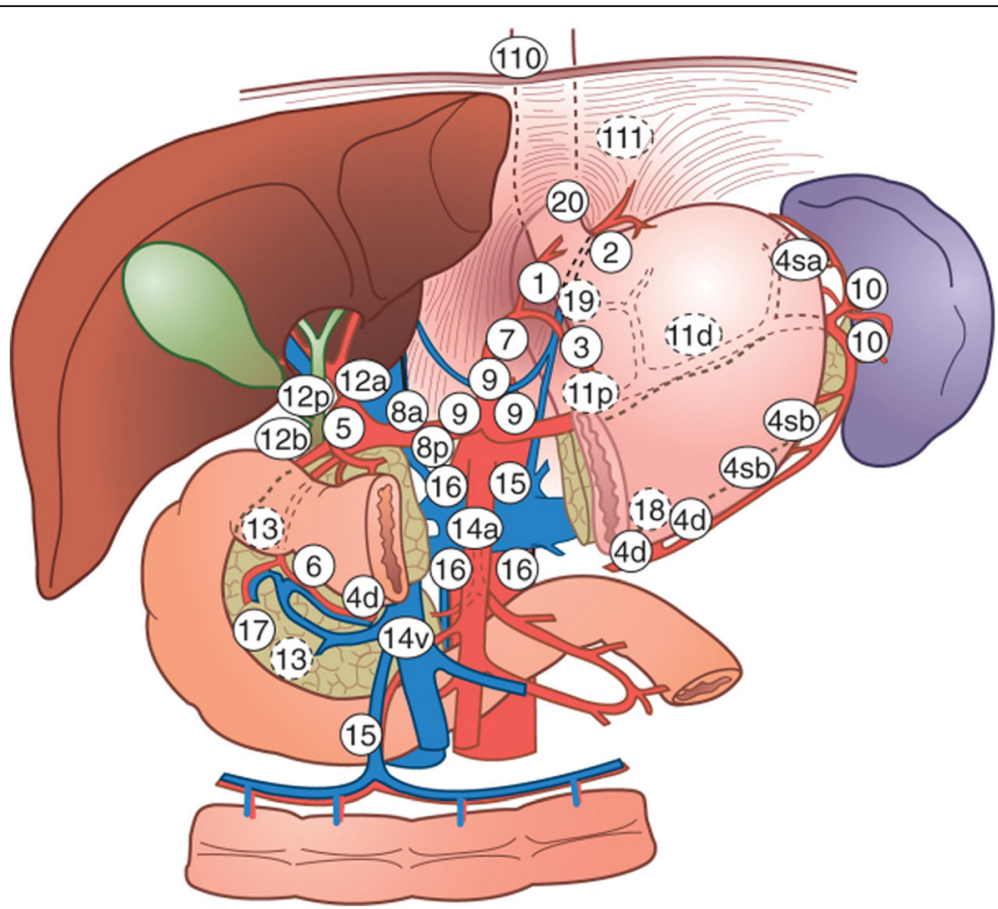

Fig. 1 Schematic diagram of lymph node station. LN, lymph node; 1 right cardiac nodes; 2 left cardiac nodes; 3 nodes along the lesser curvature; 4 nodes along the greater curvature; 5 suprapyloric nodes; 6 infrapyloric nodes; 7 nodes along root left gastric artery; 8 nodes along common hepatic artery; 9 nodes around celiac axis; 10 nodes at splenic hilum; 11 lymph nodes along the proximal SA; 12 nodes at the hepatoduodenal ligament; 13 nodes on the posterior surface of the pancreatic head; 14 lymph nodes along the SMA or superior mesenteric vein; 15 nodes along the middle colic vein; 16a lymph nodes around the abdominal aorta for the upper margin of the celiac trunk to the lower margin of the LRV; $16 \mathrm{~b}$ lymph nodes around the abdominal aorta from the upper margin of the LRV to the aortic bifurcation; 110 lymph nodes in the lower thoracic paraesophageal; 20 lymph nodes in the esophageal hiatus of the diaphragm [46]

subtotal gastrectomy, no. 2 LNs should be contained in CTV.

Current studies recommended that the target volume for postoperative RT in gastric cancer covered all nodal recurrence sites. Node nos. 1-6, 10, and 11 can be excluded from the treatment volume because of the extremely low recurrence rate after surgery. Jeong reassessed the ARTIST trial depending on the patterns of postoperative recurrence and the definition of the target volume [30]. The study found that the ARTIST trial was similar to the study of Yoon in failure patterns, and the postoperative concomitant radiochemotherapy significantly decreased the recurrence rate of node nos. $16 \mathrm{a} / \mathrm{b}$, 13 , and 14 compared with chemotherapy alone. This result indicates that RT has advantages in the control of high-risk lymph node.

According to Yoon, if the tumor involved the proximal third stomach, then the lymph nodes for target volume should include $9,10,13$, and $16 \mathrm{a} / \mathrm{b}$. If the gastric cancer involved the middle third stomach, then the extent should include 12, 14, and 16a/b. If the tumor involved the distal third stomach, then the extent should include $9,11-14$, and $16 \mathrm{a} / \mathrm{b}$. If the gastric cancer involved more than two-thirds of stomach, then 2 ,
$9,11,12,14$, and $16 \mathrm{a} / \mathrm{b}$ should be included (Table 4). In the present study, a preliminary plan can be recommended. The anastomotic site should be included because of a high rate of recrudesce. Whether the residual stomach should be irradiated remains controversial, and IMRT can reduce the adverse reactions. The tumor bed should be included for the T4 stage. No deal exists either on the extent of lymph nodes for RT.

Additionally, a phase II trial from China provides a new method to contouring the target volumes of lymph node for postoperative RT in gastric cancer [47]. Compared with the traditional surgical-based division system, the stomach is segmented into the upper third-fundus, the middle third-body, and the lower third-pylorus. They

Table 4 Radiation range of lymph nodes after D2 dissection from Yoon

\begin{tabular}{ll}
\hline Primary site & Radiation range \\
\hline Proximal third stomach & $9,10,13$, and $16 \mathrm{a} / \mathrm{b}$ \\
Middle third stomach & 12,14 , and 16a/b \\
Distal third stomach & $9,11-14$, and 16a/b \\
More than two-thirds of the stomach & $2,9,11,12,14$, and 16a/b \\
\hline
\end{tabular}


advised that the target volumes should always contain the perigastric LNs (nos. 1-6) and the lymphatics in the gastric wall and the LNs around the celiac artery. The other LNs should be irradiated on the basis of their lymphatic drainage.

A preliminary plan from our hospital advises the following points. The gastric cancer involving the proximal third stomach should include 110, 20, 1-3, 7-11, and $16 \mathrm{a} / \mathrm{b}$. The gastric cancer involving the middle third stomach should include 1, 3, 5, 9, 11p, 12, 13, 14 (T4 or pancreas involved), and $16 \mathrm{a} / \mathrm{b}$. The gastric cancer involving the distal third stomach should include 3 , $5,9,11 \mathrm{p}, 12,13,14$ (T4 or pancreas involved), and 16a/ b (Table 5). The effect of this plan has not been reported, and researchers can enlighten the updating path of delineating lymph node target volumes.

An improved plan for target volumes delineation should be on the basis of clinical experience and the characteristics of lymphatic drainage. Currently, the study of Yoon et al. is the only research on delineating the rnGTV, but they analyzed only the patients with stage III (N3) gastric cancer. The study of $\mathrm{Yu}$ provides a new idea for delineating lymph node target volumes; however, the research is single-arm, phase II, and non-randomized. Phase III trials are still necessary to validate the conclusion. The guidelines for the delineation of target volumes for postoperative RT entail further consensus.

\section{Conclusion}

Preoperative RT has progressed in treating GEJ cancer; however, the application of preoperative RT still lacks large-scale phase III clinical trials for gastric cancer. In addition, patients with D1 or D1 plus lymphadenectomy can benefit from postoperative RT obviously, and postoperative RT may be beneficial for some patients with D2 lymphadenectomy. Multicenter randomized controlled trials are still required to confirm the value of RT in patients with this disease.

$\mathrm{RT}$ is a promising prospect as a local treatment option; future efforts should be directed to defining the target volume, determining the optimal multimodality protocol, and improving the technology of RT. Screening for novel biomarkers of radiosensitivity will also help patients of gastric cancer benefit from personalized therapy.

Table 5 Radiation range of lymph nodes after D2 dissection from the Chinese Academy of Medical Sciences

\begin{tabular}{ll}
\hline Primary site & Radiation range \\
\hline Proximal third stomach & $110,20,1-3,7-11$, and 16a/b \\
Middle third stomach & $1,3,5,9,11 \mathrm{p}, 12,13,14^{*}$, and 16a/b \\
Distal third stomach & $3,5,9,11 \mathrm{p}, 12,13,14^{*}$, and 16a/b \\
\hline
\end{tabular}

*T4 or pancreas involved

\section{Abbreviations}

2D: 2-Dimentional irradiation; 3D: 3-Dimensional conformal radiation therapy; 5-FU: 5-Fluorouracil; CRT: Chemoradiotherapy; CT: Chemotherapy; DFS/ RFS: Disease-/relapse-free survival; EC: Esophagus cancer;

EGJ: Esophagogastric junction; GC: Gastric cancer; GEJ: Gastroesophageal junction; IMRT: Intensity-modulated radiation therapy; LNs: Lymph nodes; LRRFS: Locoregional failure-free survival; LV: Leucovorin; NR: Not reported; OS: Overall survival; RT: Radiotherapy; S: Surgery; XP: Capecitabine plus cisplatin

\section{Availability of data and materials}

All data generated or analyzed during this study are included in this published article.

\section{Authors' contributions}

$\mathrm{NZ}, \mathrm{QF}$, and XH contributed to the study conception and design. JJG and LY performed the collection of data and conducted the data interpretation. All authors contributed to the manuscript writing. All authors read and approved the final manuscript.

Ethics approval and consent to participate None.

\section{Consent for publication}

None.

\section{Competing interests}

The authors declare that they have no competing interests.

\section{Publisher's Note}

Springer Nature remains neutral with regard to jurisdictional claims in published maps and institutional affiliations.

Received: 28 March 2018 Accepted: 5 September 2018 Published online: 13 September 2018

\section{References}

1. Ferlay J, Soerjomataram I, Dikshit R, Eser S, Mathers C, Rebelo M, Parkin D, Forman D, Bray F. Cancer incidence and mortality worldwide: sources, methods and major patterns in GLOBOCAN 2012. Int J Cancer. 2015;136: E359-86.

2. Edge SB, Compton CC. The American Joint Committee on Cancer: the 7th Edition of the AJCC Cancer Staging Manual and the Future of TNM. Ann Surg Oncol. 2010;17:1471.

3. Macdonald JS, Smalley SR, Benedetti J, Hundahl SA, Estes NC, Stemmermann GN, Haller DG, Ajani JA, Gunderson LL, Jessup JM. Chemoradiotherapy after surgery compared with surgery alone for adenocarcinoma of the stomach or gastroesophageal junction. N Engl J Med. 2001;345:725-30

4. Tormo FV, Andreu Martínez FJ, Cardenal MR, Pomares AA. Evaluation of the toxicity of the combined treatment of chemoradiotherapy, according to the scheme of Macdonald, after radical surgery in patients diagnosed of gastric cancer. Clin Transl Oncol. 2006:8:611.

5. Yao JC, Mansfield PF, Pisters PW, Feig BW, Janjan NA, Crane C, Ajani JA. Combined-modality therapy for gastric cancer. Semin Surg Oncol. 2003;21:223.

6. Zhang ZX, Gu XZ, Yin WB, Huang GJ, Zhang DW, Zhang RG. Randomized clinical trial on the combination of preoperative irradiation and surgery in the treatment of adenocarcinoma of gastric cardia (AGC)--report on 370 patients. Int J Radiat Oncol Biol Phys. 1998;42:929-34.

7. Stahl M, Walz MK, Stuschke M, Lehmann N, Meyer HJ, Rieraknorrenschild J, Langer P, Engenhartcabillic R, Bitzer M, Königsrainer A. Phase III comparison of preoperative chemotherapy compared with chemoradiotherapy in patients with locally advanced adenocarcinoma of the esophagogastric junction. J Clin Oncol Off J Am Soc Clin Oncol. 2009;27:851.

8. Van HP, Hulshof MC, van Lanschot JJ, Steyerberg EW, Mi VBH, Wijnhoven BP, Richel DJ, Nieuwenhuijzen GA, Hospers GA, Bonenkamp JJ. Preoperative chemoradiotherapy for esophageal or junctional cancer. N Engl J Med. 2012;367:737-42. 
9. Skoropad V, Berdov B, Zagrebin V. Concentrated preoperative radiotherapy for resectable gastric cancer: 20-years follow-up of a randomized trial. J Surg Oncol. 2002;80:72-8.

10. JA A, PF M, N J JM, PW P, PM L, B F RM, R N DSC, LL G. Multiinstitutional trial of preoperative chemoradiotherapy in patients with potentially resectable gastric carcinoma. J Clin Oncol Off J Am Soc Clin Oncol. 2004;22:2774

11. Ajani JA, Mansfield PF, Crane CH, Wu TT, Lunagomez S, Lynch PM, Janjan N, Feig B, Faust J, Yao JC. Paclitaxel-based chemoradiotherapy in localized gastric carcinoma: degree of pathologic response and not clinical parameters dictated patient outcome. J Clin Oncol Off J Am Soc Clin Oncol. 2005;23:1237.

12. Balandraud $P$, Moutardier $V$, Giovannini M, Giovannini MH, Lelong B, Guiramand J, Magnin V, Houvenaeghel G, Delpero JR. Locally advanced adenocarcinomas of the gastric cardia: results of pre-operative chemoradiotherapy. Gastroenterol Clin Biol. 2004;28:651.

13. Klautke G, Foitzik T, Ludwig K, Ketterer P, Klar E, Fietkau R. Neoadjuvant radiochemotherapy in locally advanced gastric carcinoma. Strahlenther Onkol. 2004;180:695-700.

14. Lowy AM, Feig BW, Janjan N, Rich TA, Pisters PW, Ajani JA, Mansfield PF. A pilot study of preoperative chemoradiotherapy for resectable gastric cancer. Ann Surg Oncol. 2001;8:519.

15. Kumagai K, Rouvelas I, Tsai JA, Mariosa D, Lind PA, Lindblad M, Ye W, Lundell $\mathrm{L}$, Schuhmacher C, Mauer M. Survival benefit and additional value of preoperative chemoradiotherapy in resectable gastric and gastrooesophageal junction cancer: a direct and adjusted indirect comparison meta-analysis. Eur J Surg Oncol J Eur Soc Surg Oncol Br Assoc Surg Oncol. 2015;41:282-94.

16. Fiorica F, Cartei F, Enea M, Licata A, Cabibbo G, Carau B, Liboni A, Ursino S. The impact of radiotherapy on survival in resectable gastric carcinoma: a meta-analysis of literature data. Cancer Treat Rev. 2007;33:729.

17. Cunningham D, Allum WH, Stenning SP, Thompson JN, Cj VDV, Nicolson M, Scarffe JH, Lofts FJ, Falk SJ, Iveson TJ. Perioperative chemotherapy versus surgery alone for resectable gastroesophageal cancer. J Evid Based Med. 2008;355:11

18. Ychou M, Boige V, Pignon JP, Conroy T, Bouché $\mathrm{O}$, Lebreton G, Ducourtieux M, Bedenne L, Fabre JM, Saintaubert B. Perioperative chemotherapy compared with surgery alone for resectable gastroesophageal adenocarcinoma: an FNCLCC and FFCD multicenter phase III trial. J Clin Oncol Off J Am Soc Clin Oncol. 2011;29:1715-21.

19. Schuhmacher $C$, Gretschel S, Lordick F, Reichardt P, Hohenberger W, Eisenberger CF, Haag C, Mauer ME, Hasan B, Welch J. Neoadjuvant chemotherapy compared with surgery alone for locally advanced cancer of the stomach and cardia: European Organisation for Research and Treatment of Cancer Randomized Trial 40954. J Clin Oncol Off J Am Soc Clin Oncol. 2010;28:5210-8.

20. Australasian Gastro-Intestinal Trials Group. Trial of preoperative therapy for gastric and esophagogastric junction adenocarcinoma (TOPGEAR) [http:// clinicaltrials.gov/show/NCT01924819]. Accessed 1 Aug 2017.

21. Zhou Z. Pre-operative chemoradiotherapy or chemotherapy following surgery and adjuvant chemotherapy in patients with gastric cancer [http:// clinicaltrials.gov/ct2/show/NCT01815853]. Accessed 1 Aug 2017.

22. Songun I, Putter $H$, Kranenbarg EM, Sasako M, Cj VDV. Surgical treatment of gastric cancer: 15-year follow-up results of the randomised nationwide Dutch D1D2 trial. Lancet Oncol. 2010;11:404-5.

23. Smalley SR, Benedetti JK, Haller DG, Hundahl SA, Estes NC, Ajani JA, Gunderson LL, Goldman B, Martenson JA, Jessup JM. Updated analysis of SWOG-directed intergroup study 0116: a phase III trial of adjuvant radiochemotherapy versus observation after curative gastric cancer resection. J Clin Oncol Off J Am Soc Clin Oncol. 2012;30:2327-33.

24. Lee J, Lim DH, Kim S, Park SH, Park JO, Park YS, Lim HY, Min GC, Sohn TS, Noh JH. Phase III trial comparing capecitabine plus cisplatin versus capecitabine plus cisplatin with concurrent capecitabine radiotherapy in completely resected gastric cancer with D2 lymph node dissection: the ARTIST Trial. J Clin Oncol Off J Am Soc Clin Oncol. 2012;30:268-73.

25. Park SH, Sohn TS, Lee J, Lim DH, Hong ME, Kim K, Sohn I, Jung SH, Choi $M G$, Lee JH. Phase III trial to compare adjuvant chemotherapy with capecitabine and cisplatin versus concurrent chemoradiotherapy in gastric cancer: final report of the adjuvant chemoradiotherapy in stomach tumors trial, including survival and subset analyses. J Clin Oncol Off J Am Soc Clin Oncol. 2015;33:3130-6
26. Kim TH, Park SR, Ryu KW, Kim YW, Bae JM, Lee JH, Choi IJ, Kim YJ, Kim DY. Phase 3 trial of postoperative chemotherapy alone versus chemoradiation therapy in stage III-IV gastric cancer treated with R0 gastrectomy and D2 Jymph node dissection. Int J Radiat Oncol Biol Phys. 2012;84:585-92.

27. Zhu WG, Xua DF, Pu J, Zong CD, Li T, Tao GZ, Ji FZ, Zhou XL, Han JH, Wang CS. A randomized, controlled, multicenter study comparing intensitymodulated radiotherapy plus concurrent chemotherapy with chemotherapy alone in gastric cancer patients with D2 resection. Radiother Oncol J Eur Soc Ther Radiol Oncol. 2012;104:361-6.

28. Amini A, Jones BL, Stumpf P, Leong S, Lieu CH, Weekes C, Davis SL, Messersmith WA, Purcell WT, Ghosh D, et al. Patterns of care for locally advanced pancreatic adenocarcinoma using the National Cancer Database. Pancreas. 2017:46:904-12.

29. Sasako M, Sakuramoto S, Katai H, Kinoshita T, Furukawa H, Yamaguchi T, Nashimoto A, Fujii M, Nakajima T, Ohashi Y. Five-year outcomes of a randomized phase III trial comparing adjuvant chemotherapy with S-1 versus surgery alone in stage II or III gastric cancer. J Clin Oncol Off J Am Soc Clin Oncol. 2011;29:4387.

30. Datta J, Mcmillan MT, Ruffolo L, Lowenfeld L, Mamtani R, Plastaras JP, Dempsey DT, Karakousis GC, Drebin JA, Fraker DL. Multimodality therapy improves survival in resected early stage gastric cancer in the United States. Ann Surg Oncol. 2016;23:1-10.

31. Phase III randomized trial of adjuvant chemotherapy with S-1 vs. S-1/ oxaliplatin \pm radiotherapy for completely resected gastric adenocarcinoma: the ARTIST II trial (ARTIST-II) [http://clinicaltrials.gov/ct2/show/NCT01761461]. Accessed 1 Aug 2017.

32. Shim HJ, Kim KR, Hwang JE, Bae WK, Ryu SY, Park YK, Nam TK, Chung IJ, Cho SH. A phase II study of adjuvant S-1/cisplatin chemotherapy followed by S-1-based chemoradiotherapy for D2-resected gastric cancer. Cancer Chemother Pharmacol. 2016;77:605-12.

33. Ohri N, Garg MK, Aparo S, Kaubisch A, Tome W, Kennedy TJ, Kalnicki S, Guha C. Who benefits from adjuvant radiation therapy for gastric cancer? A meta-analysis. Int J Radiat Oncol Biol Phys. 2013;86:330-5.

34. Pang X, Wei W, Leng W, Chen Q, Xia H, Chen L, Li R. Radiotherapy for gastric cancer: a systematic review and meta-analysis. Tumour Biol J Int Soc Oncodev Biol Med. 2014;35:387-96.

35. Soon YY, Leong CN, Tey JC, Tham IW, Lu JJ. Postoperative chemoradiotherapy versus chemotherapy for resected gastric cancer: a systematic review and meta-analysis. J Med Imaging Radiat Oncol. 2014;58:483.

36. Lee J, Park CK, Park JO, Lim T, Park YS, Lim HY, Lee I, Sohn TS, Noh JH, Heo JS. Impact of E2F-1 expression on clinical outcome of gastric adenocarcinoma patients with adjuvant chemoradiation therapy. Clin Cancer Res. 2008;14:82.

37. Gordon MA, Gundacker HM, Benedetti J, Macdonald JS, Baranda JC, Levin WJ, Blanke CD, Elatre W, Weng P, Zhou JY. Assessment of HER2 gene amplification in adenocarcinomas of the stomach or gastroesophageal junction in the INT-0116/SWOG9008 clinical trial. Ann Oncol. 2013;24:1754.

38. Bargielaiparraguirre J, Pradomarchal L, Fernandezfuente M, Gutierrezgonzález A, Morenorubio J, Muñozfernandez M, Sereno M, Sanchezprieto R, Perona R, Sanchezperez I. CHK1 expression in gastric cancer is modulated by p53 and RB1/E2F1: implications in chemo/ radiotherapy response. Sci Rep. 2016;6:21519.

39. Matzinger $O$, Gerber $E$, Bernstein Z, Maingon P, Haustermans $K$, Bosset JF, Gulyban A, Poortmans P, Collette L, Kuten A. EORTC-ROG expert opinion: radiotherapy volume and treatment guidelines for neoadjuvant radiation of adenocarcinomas of the gastroesophageal junction and the stomach. Radiother Oncol J Eur Soc Therap Radiol Oncol. 2009;92:164-75.

40. Oppedijk V, van der Gaast A, van Lanschot JJ, van Hagen P, van Os R, van Rij CM, van der Sangen MJ, Beukema JC, Rütten H, Spruit PH. Patterns of recurrence after surgery alone versus preoperative chemoradiotherapy and surgery in the CROSS trials. J Clin Oncol Off J Am Soc Clin Oncol. 2014;32:385.

41. Smalley SR, Gunderson L, Tepper J, Jr MJ, Minsky B, Willett C, Rich T. Gastric surgical adjuvant radiotherapy consensus report: rationale and treatment implementation. Int J Radiat Oncol Biol Phys. 2002;52:283-93.

42. Tepper JE, Gunderson LL. Radiation treatment parameters in the adjuvant postoperative therapy of gastric cancer. Semin Radiat Oncol. 2002;12:187.

43. Nam H, Lim-Do H, Kim S, Kang W, Sohn T, Noh J, Kim Y, Park C, Park C, Ahn $Y$, Huh S. A new suggestion for the radiation target volume after a subtotal gastrectomy in patients with stomach cancer. Int J Radiat Oncol Biol Phys. 2008;71:448-55. 
44. Ohira M, Toyokawa T, Sakurai K, Kubo N, Tanaka H, Muguruma K, Yashiro M, Onoda N, Hirakawa K. Current status in remnant gastric cancer after distal gastrectomy. World J Gastroenterol. 2016;22:2424.

45. Chang JS, Lim JS, Noh SH, Hyung WJ, An JY, Lee YC, Rha SY, Lee CG, Koom WS. Patterns of regional recurrence after curative D2 resection for stage III (N3) gastric cancer: implications for postoperative radiotherapy. Radiother Oncol J Eur Soc Therap Radiol Oncol. 2012;104:367-73.

46. Yoon HI, Chang JS, Lim JS, Noh SH, Hyung WJ, An JY, Lee YC, Rha SY, Kim $\mathrm{KH}$, Koom WS. Defining the target volume for post-operative radiotherapy after D2 dissection in gastric cancer by CT-based vessel-guided delineation. Radiother Oncol J Eur Soc Therap Radiol Oncol. 2013;108:72-7.

47. Haijun Y, Qiuji W, Zhenming F, Yong H, Zhengkai L, Conghua X, Yunfeng Z, Yahua Z. A new approach to delineating lymph node target volumes for post-operative radiotherapy in gastric cancer: a phase II trial. Radiother Oncol J Eur Soc Therap Radiol Oncol. 2015;116:245.

Ready to submit your research? Choose BMC and benefit from:

- fast, convenient online submission

- thorough peer review by experienced researchers in your field

- rapid publication on acceptance

- support for research data, including large and complex data types

- gold Open Access which fosters wider collaboration and increased citations

- maximum visibility for your research: over $100 \mathrm{M}$ website views per year

At $\mathrm{BMC}$, research is always in progress.

Learn more biomedcentral.com/submissions 